\title{
Measurement and Kinetics of Elemental and Atomic Potassium Release from a Burning Biomass Pellet
}

Yingzu Liu ${ }^{1,2}$, Zhihua Wang ${ }^{1, *}$, Jun Xia ${ }^{2, *}$, Luc Vervisch ${ }^{3}$, Kaidi Wan ${ }^{1}$, Yong $\mathrm{He}^{1}$, Ronald Whiddon ${ }^{1}$, Hamid Bahai ${ }^{2}$, Kefa Cen ${ }^{1}$

1 State Key Laboratory of Clean Energy Utilization, Zhejiang University, 310027, Hangzhou, P.R. China 2 Department of Mechanical and Aerospace Engineering \& Institute of Energy Futures, Brunel University London, Uxbridge UB8 3PH, UK 3 CORIA - CNRS, Normandie Université, INSA de Rouen, 76800 Saint-Etienne-du-Rouvray, France

* Corresponding authors:

(1) Zhihua Wang, Tel: +86-571-87953162, Fax: +86-571-8795-1616, Email: wangzh@,zju.edu.cn;

(2) Jun Xia, Tel: +44(0)1895-265-433, Fax: +44(0)1895-256-392, Email: jun.xia@,brunel.ac.uk

\section{Colloquium: Solid Fuel Combustion}

\section{Word counts by method 1:}

Main Text:

6132

Equations:

46

References:

454

Nomenclature:

152

Tables:

296

Figures:

1226, including Fig. 1: 169, Fig. 2: 184, Fig. 3: 223, Fig. 4: 190, Fig. 5: 133, Fig. 6: 125, Fig. 7: 200.

Tables:

Table 1 Chemical analyses of biomass samples.

\begin{tabular}{|c|c|c|c|c|c|c|c|c|c|c|}
\hline & & \multicolumn{4}{|c|}{ Proximate analysis (wt.\%) } & \multicolumn{5}{|c|}{ Ultimate analysis (wt.\%) } \\
\hline & & $M_{a d}$ & $A_{a d}$ & $V_{a d}$ & $F C_{a d}$ & $C_{\text {daf }}$ & $H_{d a f}$ & $N_{d a f}$ & $S_{d a f}$ & $O_{\text {daf }}$ \\
\hline \multicolumn{2}{|c|}{ Corn Straw (CS) } & 11.6 & 7.9 & 64.2 & 16.3 & 43.9 & 4.5 & 1.8 & 0.4 & 49.3 \\
\hline \multicolumn{2}{|c|}{ Poplar } & 11.6 & 2.3 & 66.3 & 19.8 & 45.9 & 4.1 & 0.7 & 0.1 & 49.2 \\
\hline \multicolumn{9}{|c|}{ Ash analysis (wt.\%) } & $C l_{a d}$ & $K_{a d}$ \\
\hline & $\mathrm{SiO}_{2}$ & $\mathrm{Al}_{2} \mathrm{O}_{3}$ & $\mathrm{Fe}_{2} \mathrm{O}_{3}$ & $\mathrm{CaO}$ & $\mathrm{MgO}$ & $\mathrm{K}_{2} \mathrm{O}$ & $\mathrm{Na}_{2} \mathrm{O}$ & & $(\mathrm{mg} / \mathrm{g})$ & $(\mathrm{mg} / \mathrm{g})$ \\
\hline $\mathrm{CS}$ & 47.52 & 5.64 & 1.04 & 4.51 & 12.6 & 7.87 & 1.97 & CS & 1.34 & 13.1 \\
\hline Poplar & 30.97 & 5.09 & 2.6 & 29.32 & 5.96 & 6.94 & 2.9 & Poplar & 1.04 & 7.09 \\
\hline
\end{tabular}


Table 2 Potassium release in different burning stages (raw biomass pellet: $50 \mathrm{mg}$ )

\begin{tabular}{ccccccc}
\hline & \multicolumn{3}{c}{ Poplar } & \multicolumn{3}{c}{ Corn Straw } \\
\cline { 2 - 7 } & devol & $C \& A$ & total & devol & $C \& A$ & total \\
\hline Atomic K $(\mu \mathrm{g})$ & 1.02 & 1.28 & 2.30 & 2.68 & 2.07 & 4.76 \\
Elemental K $(\mu \mathrm{g})$ & 140 & 150 & 290 & 360 & 260 & 620 \\
$K^{A}$ Proportion $(\%)$ & 0.73 & 0.85 & 0.79 & 0.74 & 0.80 & 0.77 \\
$K^{A}$ Proportion $(\%)$ & & & 0.68 at $1892 \mathrm{~K}$ & \\
by CHEMKIN & & & & & \\
\hline
\end{tabular}

Table 3 Kinetics parameters of two models for biomass samples.

\begin{tabular}{lll}
\hline \multicolumn{1}{c}{ Kinetics Model } & Poplar & Corn Straw \\
\hline one-step: & & \\
$\left\{\begin{array}{lll}K_{f l u x}^{\Sigma}=Q_{K} \times k_{V} & A_{V}=4.64 & A_{V}=2.24 \\
Q_{K}=K_{a d} \times m \times\left(1-A_{a d}\right) & E_{V}=84.6 & E_{V}=64.8 \\
k_{V}=A_{V} \times \exp \left(-E_{V} /(R \times T)\right) & & \\
\hline\end{array}\right.$
\end{tabular}

two-step:

$\left\{\begin{array}{lcc}K_{f l u x}^{\sum}=Q_{K, V} \times k_{V}+Q_{K, C \& A} \times k_{C \& A} & A_{V}=4.64 & A_{V}=2.24 \\ Q_{K, V}=K_{a d} \times m \times\left(1-A_{a d}\right) \times V_{a d} & E_{V}=84.6 & E_{V}=64.8 \\ Q_{K, C \& A}=K_{a d}-Q_{K, V} & A_{C \& A}=20.5 & A_{C \& A}=15.3 \\ k_{V}=A_{V} \times \exp \left(-E_{V} /(R \times T)\right) & E_{C \& A}=55.4 & E_{C \& A}=62.8 \\ k_{C \& A}=A_{C \& A} \times \exp \left(-E_{C \& A} /(R \times T)\right) & & \end{array}\right.$

\section{Nomenclature}

\begin{tabular}{ccc}
\hline$K^{\Sigma}$ & Elemental potassium & - \\
{$\left[K^{\Sigma}\right]$} & Elemental potassium concentration & $\mathrm{mg} / \mathrm{m}^{3}$ \\
$K^{\Sigma_{f l u x}}$ & Elemental potassium flux & $\mathrm{mg} / \mathrm{s}$ \\
$K^{A}$ & Atomic potassium & - \\
{$\left[K^{A}\right]$} & Atomic potassium concentration & $\mathrm{mg} / \mathrm{m}^{3}$ \\
$K^{A} f l u x$ & Elemental potassium flux & $\mathrm{mg} / \mathrm{s}$ \\
$Q_{K}$ & Released total potassium mass & $\mathrm{mg}$ \\
$k$ & rate constants & $\mathrm{s}^{-1}$ \\
$A$ & pre-exponential factor & $\mathrm{s}^{-1}$ \\
$E$ & activation energy & $\mathrm{kJ} / \mathrm{mol}^{-1}$ \\
$R$ & gas constant & $\mathrm{kJ} \mathrm{mol} \mathrm{K}^{-1}$ \\
$I_{L I B S, K}$ & Potassium Signal in LIBS & $\mathrm{a} \cdot \mathrm{u}$. \\
$T$ & Surface temperature & $\mathrm{K}$ \\
& Subscripts & \\
$V$ & Devolatilization stage & - \\
$C \& A$ & Char and Ash stage & - \\
\hline
\end{tabular}




\section{Figure captions:}

38 Fig. 1 Experimental setup of K-PLIF measurements for biomass pellet combustion: (1) OPO laser, (2) Polarizer, (3)

39 Prism, (4) Cylindrical Lens, (5) Spherical Lens, (6) Beam Sampler, (7) PD, (8) ICCD, (9) Burner, (10) Trap, (11)

40 Oscilloscope.

41 Fig. 2 Effects of polarizer on the fluorescence signal for corn straw pellet for cases: $\mathbf{m}$ on $\mathrm{K}$ spectral line resonance

42 measurement with polarizer, $\bullet$ off $\mathrm{K}$ spectral line resonance measurement with polarizer, $\Delta$ on $\mathrm{K}$ spectral line

43 resonance measurement without polarizer, $\nabla$ off $\mathrm{K}$ spectral line resonance measurement without polarizer. The

44 solid line is the signal to background ratio with polarizer and the dash line is signal to background ratio without

45 polarizer.

46 Fig. 3 The $2 \mathrm{D}$ atomic $\mathrm{K}$ distribution and release history measured by PLIF

$47 \quad$ Fig. 4 Profile of $K^{\Sigma_{f l u x}}$ and statistics of $K^{\Sigma}$ release in different biomass-burning stages.

48 Fig. 5 Variation of pellet surface temperature $(T)$ and $K^{\sum_{f l u x}}$ with time. - --: Corn Straw surface temperature;

49 Poplar surface temperature; dash line: corn straw potassium release flux; solid line: poplar potassium release flux.

50 Fig. 6 Kinetic prediction of potassium release compared to LIBS data.

51 Fig. 7 Suggested potassium transformation mechanisms during biomass combustion. 
Abstract

Combining polarizing-filtered planar laser-induced fluorescence (PLIF) with simultaneous laser absorption, quantitative laser-induced breakdown spectroscopy (LIBS) and two-color pyrometry, the potassium release during the combustion of biomass fuels (corn straw and poplar) has been investigated. The temporal release profiles of volatile atomic potassium and potassium compounds from a corn straw show a single peak. The woody biomass, poplar, produces a dual-maxima distribution for potassium and potassium compounds. For both biomass samples, the highest concentrations of released atomic potassium and potassium compounds occur in the devolatilization stage. The mass ratios between volatile atomic potassium and potassium compounds in the corn straw and poplar cases are $0.77 \%$ and $0.79 \%$, respectively. These values agree well with chemical equilibrium predictions that $0.68 \%$ of total potassium will be in atomic form. A two-step kinetic model of potassium release has been developed, which gives better predictions during the devolatilization stage than the existing single-step model. Finally, a map of potassium transformation processes during combustion is developed. Starting with inorganic and organic potassium, there are eight proposed transformation pathways including five proposed release pathways that occur during the combustion. The pathways describe the transformation of potassium between the fuel volatile matter, char, and ash.

67 Potassium release during the devolatilization stage is due to pyrolysis and evaporation; during the char burnout stage, release is due to char oxidation and decomposition; and during the ash cooking stage, potassium release is caused by reactions between the ash and $\mathrm{H}_{2} \mathrm{O}$ in the co-flow. 


\begin{tabular}{ccc}
\multicolumn{3}{c}{ Nomenclature } \\
\hline$K^{\Sigma}$ & Elemental potassium & - \\
{$\left[K^{\Sigma}\right]$} & Elemental potassium concentration & $\mathrm{mg} / \mathrm{m}^{3}$ \\
$K^{\Sigma_{f l u x}}$ & Elemental potassium flux & $\mathrm{mg} / \mathrm{s}$ \\
$K^{A}$ & Atomic potassium & - \\
{$\left[K^{A}\right]$} & Atomic potassium concentration & $\mathrm{mg} / \mathrm{m}^{3}$ \\
$K_{f f l u x}^{A}$ & Elemental potassium flux & $\mathrm{mg} / \mathrm{s}$ \\
$Q_{K}$ & Released total potassium mass & $\mathrm{mg}$ \\
$k$ & rate constants & $\mathrm{s}^{-1}$ \\
$A$ & pre-exponential factor & $\mathrm{s}^{-1}$ \\
$E$ & activation energy & $\mathrm{kJ} / \mathrm{mol}^{-1}$ \\
$R$ & gas constant & $\mathrm{kJ} \mathrm{mol}{ }^{-1} \mathrm{~K}^{-1}$ \\
$I_{L I B S, K}$ & Potassium Signal in LIBS & a.u. \\
$T$ & Surface temperature & $\mathrm{K}$ \\
Subscripts & & \\
$V$ & Devolatilization stage & - \\
$C \& A$ & Char and Ash stage & - \\
\hline
\end{tabular}

\section{Introduction}

Biomass fuels currently supply $10-15 \%$ of the world energy demand [1], with increased use in thermal power production as a renewable fuel source. However, advanced biomass utilization is hampered by ash formation and deposition problems [2]. Compared to solid fuels like coal, biomass has elevated levels of alkali elements, particularly potassium. Alkali compounds that are released during combustion condense on heat exchange surfaces, causing fouling and corrosion. For instance, the potassium vapor will nucleate with $\mathrm{Cl}^{-}$or $\mathrm{CO}_{3}{ }^{2-}$, forming $\mathrm{KCl}$ or

$81 \mathrm{~K}_{2} \mathrm{CO}_{3}$, which is easy to evaporate and condense on heat exchanger surfaces and causes serious corrosion.

82 Understanding the release dynamics and transformation of potassium during biomass combustion is essential for better utilization of this renewable fuel resource.

The release of potassium during biomass combustion has been studied using various offline and online measurement methods [2]. Since the agricultural biomass tends to have much higher (1\% or more) potassium proportion than Woody biomass (near $0.1 \%$ ), The release characteristic of potassium from woody and agricultural 
87 biomass is very different $[3,4]$. Numerous non-intrusive, time-resolved optical diagnostics techniques have been

used to study the release characteristic of elemental alkali and alkali compounds, such as laser induced fragmentation fluorescence (ELIF) [5], collinear photo-fragmentation atomic absorption spectroscopy (CPFAAS) [6], tunable diode laser absorption spectroscopy (TDLAS) [7], planar laser-induced fluorescence (PLIF) [8] and laser-induced breakdown spectroscopy (LIBS) $[9,10]$.

van Eyk et al. coupled quantitative PLIF of atomic sodium in a burning coal pellet with simultaneous temperature measurement and developed a one-step atomic sodium release model [11]. Similarly, Zhang et al. [12] quantitatively measured potassium release in the combustion of a pinewood pellet and obtained a one-step Arrhenius rate law for the volatile potassium release. These accomplishments have added greatly to the scientific understanding of alkali species release during solid-fuel combustion. However, quantitative measurement of potassium release during the start of combustion is noticeably lacking, as is a kinetic model to predict this initial release.

In our previous studies, simultaneous multi-point LIBS and pellet-surface temperature measurements were applied to develop the kinetics of sodium release from a sodium-rich Zhundong coal pellet [13]. Additionally, quantitative PLIF was employed to investigate the atomic sodium release mechanism [14]. In this study, quantitative PLIF and multi-point LIBS are used to determine the volatile potassium flux from a burning biomass pellet and the pellet surface temperature is measured by two-color pyrometry. From these combined measurements, an empirical model for the kinetics of potassium release is deduced. A discussion of likely potassium transformation processes is included.

\section{Experimental setup}

\subsection{Biomass Fuel}

Corn straw and poplar were used as representative biomass fuel, representing agricultural class and forest class biomass, respectively. The proximate analysis and ultimate analysis, as well as the mass fractions of chlorine and 
111 potassium of the two samples, are listed in Table 1. The potassium and chlorine concentrations were measured by

112 ICP-AES (Thermo Scientific, iCAP 6300). For combustion measurements, $50 \mathrm{mg}$ of crushed biomass $(<75 \mu \mathrm{m})$

113 was pressed into a pellet of $4 \mathrm{~mm}$ in diameter. The pellet has an approximately spherical shape and the image of a

114 4-mm pellet can be referred to in our previous work [15]. Each combustion experiment was repeated in triplicate.

115 The standard deviation was calculated from the three measurements and is included in figures when appropriate.

116 For each experiment, the pellet was firstly suspended in the measurement region and then the operated burner was moved right below the pellet. The ignition was considered to begin when the flame was in place under the pellet.

Table 1 Chemical analyses of biomass samples.

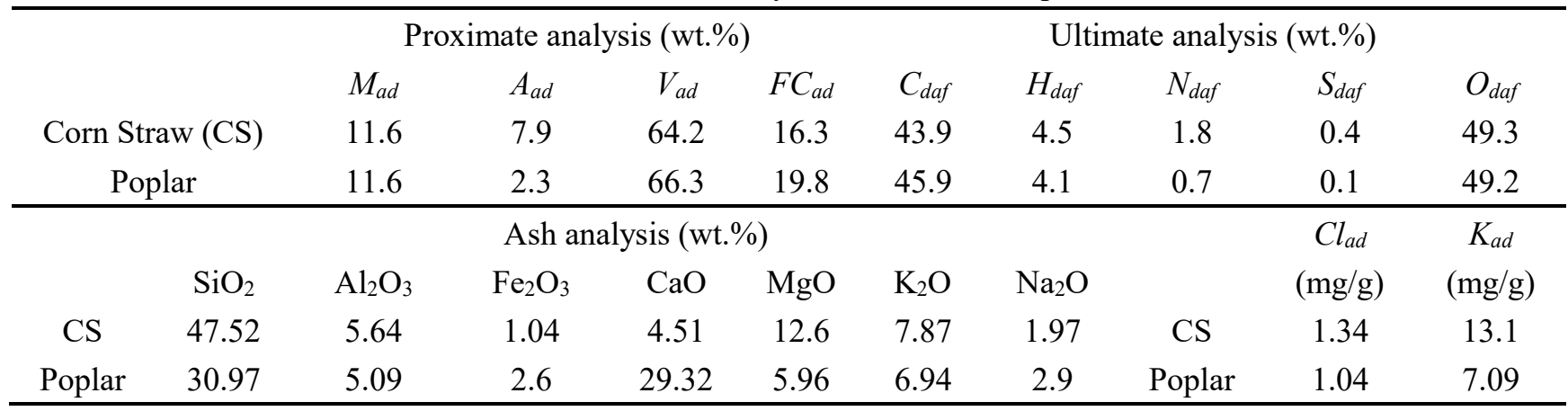

\subsection{Pellet-surface temperature measurement}

The biomass pellet is suspended on two ceramic rods ( $1 \mathrm{~mm}$ diameter) at a height of $10 \mathrm{~mm}$ above a heat flux

burner [14]. The burner produces a laminar premixed methane/air flat flame at an equivalence ratio of 0.8 for the flow rates of methane and air at $0.59 \mathrm{SL} / \mathrm{min}$ and $7.06 \mathrm{SL} / \mathrm{min}$, respectively. Using the PREMIX model in CHEMKIN with GRI-mech 3.0, the gas temperature at the height of the pellet, $12 \mathrm{~mm}$ above the burner, was estimated to be $1892 \mathrm{~K}$ for a primary gas composition of $3.9 \% \mathrm{O}_{2}, 7.6 \% \mathrm{CO}_{2}, 15.4 \% \mathrm{H}_{2} \mathrm{O}$ and $72.8 \% \mathrm{~N}_{2}$. 
A multi-point LIBS system [15] was used to measure the elemental potassium concentration $\left[K^{\Sigma}\right]\left(\mathrm{mg} / \mathrm{m}^{3}\right)$ in

the gas phase during the biomass-pellet combustion. We use $K^{\Sigma}$ to denote the potassium element appearing in all

the potassium species of the biomass volatile. The beam from an optical parametric oscillator (OPO) laser

(RADIANT HE 355UV) was tuned to the fundamental pump frequency, $1064 \mathrm{~nm}$, and focused to a point $10 \mathrm{~mm}$

above the burning biomass pellet creating the LIBS plasma. The repetition rate, pulse duration and average laser

power are $10 \mathrm{~Hz}, 10 \mathrm{~ns}$ and $300 \mathrm{~mJ} /$ pulse, respectively. The LIBS spectrum is detected with an Ocean Optics USB

4000 spectrometer. A digital pulse generator (Stanford Research System, DG535) synchronized the laser pulse to

the spectrometer gate. The laser focusing lens and signal collection optics were mounted on a power-translating

stage to allow measurements at multiple radial positions. LIBS measurements were made at $12,9,6,3$, and $0 \mathrm{~mm}$

141 from the initial measurement point $10 \mathrm{~mm}$ above the pellet center. Translation occurred between laser pulses; each position was measured at $0.5 \mathrm{~Hz}$.

The $K^{\sum}$ LIBS signal was calibrated by measuring the spectral intensity (769.9 nm) for KCl-seeded flame of a

known concentration [16]. The resulting linear response of LIBS signal to $\left[K^{\Sigma}\right]$ is:

$$
I_{L I B S, K}=1927 \times\left[K^{\Sigma}\right], R^{2}=0.97
$$

where $I_{L I B S, K}$ is the LIBS signal intensity and $R^{2}$ is the coefficient of determination.

above the burning biomass pellet was calculated from the integration of the radial $\left[K^{\Sigma}\right]$ and the gas flow rate. As

both the co-flow velocity, $u$ (predicted by a preliminary numerical simulation of this laminar flow), and $\left[K^{\Sigma}\right]$ are

functions of the radial position $r, K^{\sum_{f l u x}}$ is also defined as a function of $r$ [15]. Uncertainties in the LIBS measurement are produced by (1) non-uniform potassium distribution in the calibration flame; (2) self-absorption

by $\mathrm{K}$ atoms in the region of the plasma and (3) fluctuations of laser energy. The LIBS calibration experiment

provides values for electronic noise and uncertainty due to self-absorption. From the calibration experiment it is 
$\pm 3.6 \mathrm{e}-3 \mathrm{mg} / \mathrm{s}$ at the $\mathrm{K}$ flux of $0.03 \mathrm{mg} / \mathrm{s}$. Therefore, the uncertainty in the LIBS data will be up to

$\pm 3.6 \mathrm{e}-3 / 0.03= \pm 11.5 \%$ for different $\mathrm{K}$ fluxes. Error propagation is calculated as the square root of the quadratic sum of the maximum calibration error and the measurement standard deviation. The maximal error values of the

elemental K flux are (a) Poplar: $\pm 4.1 \mathrm{e}-4 \mathrm{mg} / \mathrm{s}( \pm 15.3 \%)$; (b) Corn Straw: $\pm 1.8 \mathrm{e}-3 \mathrm{mg} / \mathrm{s}( \pm 12.7 \%)$.

\subsection{PLIF system and calibration}

The PLIF assembly used to measuring the concentration $\left(\mathrm{mg} / \mathrm{m}^{3}\right)$ of atomic potassium $\left(K^{A}\right)$ is shown in Fig. 1.

The OPO laser was tuned to a wavelength of $769.9 \mathrm{~nm}(2.5 \mathrm{~mJ}$ per pulse after the first polarizer), to induce

fluorescence from the $K^{A}\left(4^{2} \mathrm{~S}_{1 / 2} \rightarrow 4^{2} \mathrm{P}_{1 / 2}\right)$ transition. The laser beam was formed into a 2-cm high laser sheet with

a cylindrical lens and a spherical lens. The bottom of the laser sheet $(x=0 \mathrm{~mm})$ was located at the top of the pellet.

An intensified charge-coupled device (ICCD, ISTAR-SCMOS-18U-03) with a quartz objective (Nikon

PF10545MF-UV) was used to record the fluorescence signal from the measurement region. The ICCD gate width

was set to $150 \mathrm{~ns}$ to reduce background noise from flame emission. A second polarizer mounted before the camera

was cross-oriented to the laser polarization to reject the coherent component of the Mie scattering [17].

Photodiodes (PD) were used to measure laser absorption across the measurement region.

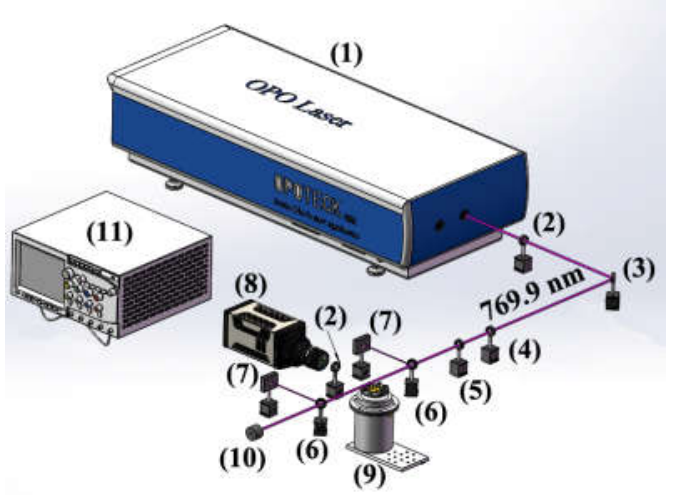

Fig. 1 Experimental setup of K-PLIF measurements for biomass pellet combustion: (1) OPO laser, (2) Polarizer, (3)

Oscilloscope. 
$\ln \left(I_{\text {out }} / I_{\text {in }}\right)=n \times \int_{\omega_{c}-b_{\omega} / 2}^{\omega_{\mathrm{c}}+b_{\omega} / 2} \sigma(\omega) d \omega \times x$

175 where $n$ is the analyte number density, $b_{\omega}$ is the bandwidth of the angular frequency, and $\sigma(\omega)$ is the 176 frequency-dependent absorption cross-section which was derived in a similar manner to the approach used in [8].

177 The integrated $\sigma(\omega)$ was measured to be $2.01 \times 10^{-19} \mathrm{~m}^{2}$. The total concentration of $K^{A}$ in the measurement region 178 was determined from the background subtracted laser absorption measurement; the quantitative spatial distribution 179 of atomic potassium was then determined by distributing the total $\left[K^{A}\right]$ according to the corrected, normalized PLIF intensity [14]. The calibration process was as follows: (1) laser absorption across the flame was used to calculate the mean atomic potassium number density; (2) off transition signal level was subtracted from the average $\mathrm{K}$ measurements to correct background noise; (3) the corrected mean atomic potassium concentration was used to determine the conversion ratio for the mean fluorescence signal; (4) the atomic potassium concentration was calculated based on the conversion ratio and the fluorescence signal in each frame.

each technique. Scatter and competing absorption/fluorescence are possible error factors causing uncertainty in both techniques, and in flame measurements are often associated with polyaromatic hydrocarbons (PAH) [7]. The atomic $\mathrm{K}$ transition wavelength is longer than the excitation wavelength for PAH fluorescence (from $\sim 200$ to 680 $\mathrm{nm}$ ) [18] and so competing absorbance/fluorescence was not found to be a major source of uncertainty in these measurements. However, scattering is significant in this resonant fluorescence measurement. Using crossed polarizers in the laser and fluorescence measurements paths can filter the highly coherent scattering signal from the incoherent fluorescence signal. The loss in signal intensity is compensated by a factor of 2.5 improvement in the signal to background ratio (Fig. 2). Scatter in the laser absorption measurement is corrected by blank subtraction.

The uncertainty of PLIF is primarily calibration uncertainty and ICCD readout noise, as laser energy fluctuation and laser energy distribution have been corrected. Using data blank and off resonance measurements [14], the 


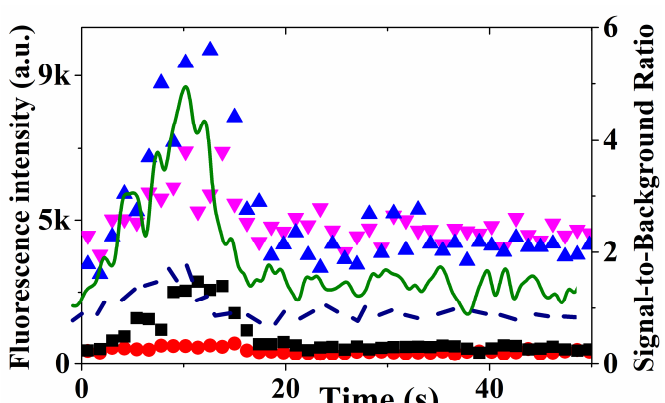

20 Time (s) 40

Fig. 2 Effects of polarizer on the fluorescence signal for corn straw pellet for cases: $\square$ on K spectral line resonance measurement with polarizer, $\bullet$ off $\mathrm{K}$ spectral line resonance measurement with polarizer, $\boldsymbol{\Delta}$ on $\mathrm{K}$ spectral line resonance measurement without polarizer, $\nabla$ off $\mathrm{K}$ spectral line resonance measurement without polarizer. The solid line is the signal to background ratio with polarizer and the dash line is signal to background ratio without polarizer.

\section{Results and discussion}

\subsection{Atomic Potassium}

Fig. 3a presents the $\left[K^{A}\right]$ distribution in the region just above the burning corn straw pellet, the average of 10 shots taken from $\mathrm{t}=12-13 \mathrm{~s}$ after ignition. The concentration decays axially and radially due to dilution and chemical reactions [19]; the highest-concentration region is slightly remote from the pellet, which was also seen during early combustion of a Zhundong coal pellet [14]. This is attributed to thermal decomposition of potassium compounds in the volatile flame above the pellet. The temporal profile of atomic potassium concentrations of the biomass samples is shown in Fig. 3b. The poplar biomass sample shows two maxima in the $K^{A}$ release, a similar trend to sodium release in coal pellet combustion [14]. In contrast, the corn straw only has a single maximum.

Solid fuel combustion may be considered to proceed in three stages: (I) devolatilization (devol.), (II) char burnout, and (III) ash cooking. The lower carbon content in biomass fuels than in coal produces a shortened char burnout stage; therefore (II) and (III) will be considered conjointly in this paper as the char and ash stage (C\&A). 


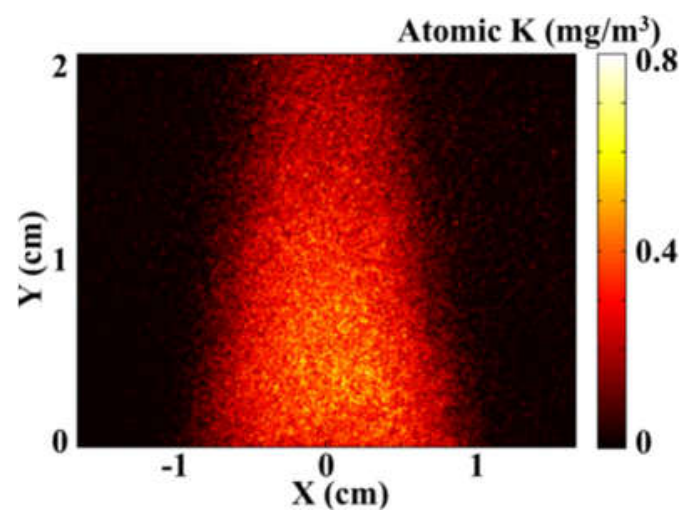

(a) 2D image of $\left[K^{A}\right]($ Corn Straw, $\mathrm{t}=12 \mathrm{~s})$

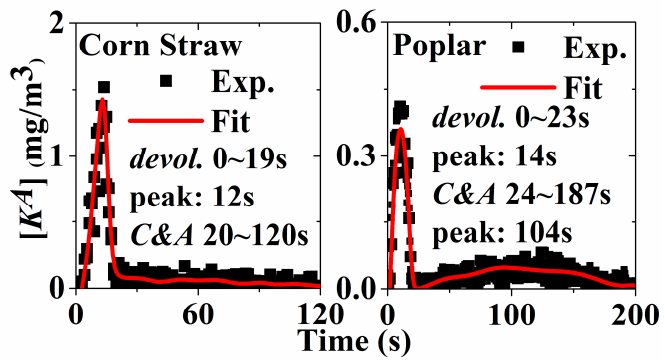

(b) Temporal $\left[K^{A}\right]$ at $\mathrm{Y}=10 \mathrm{~mm}$

Fig. 3 The 2D atomic K distribution and release history measured by PLIF

Both biomass samples have the highest $K^{A}$ release rate during the devol. stage. By the end of this combustion

221 stage, the majority of the volatile matter in the sample is depleted. Potassium is expected to be released in two ways:

222 (1) decomposition of the sample with expulsion of water and vaporized matter from the pores, and (2) increasing

pellet temperatures raise the vapor pressure of low melting point potassium compounds [20]. During the $C \& A$ stage, potassium is released from potassium compounds bound to fuel carbon compounds and inorganic potassium species in the ash. In addition, higher temperature can also enhance the excitability and production of atomic potassium. So, the $K^{A}$ peak in the $C \& A$ stage observed in the poplar case can be attributed to volatile-char interactions, char consumption and temperature increase, which is due to char burnout.

\subsection{Potassium Compounds}

As stated earlier, the LIBS technique measures species concentrations resulting from all parent compounds of 
potassium-contained species $\mathrm{K}, \mathrm{KCl}, \mathrm{KOH}$, etc. Integrating the elemental potassium concentration $\left[K^{\Sigma}\right]$ across the radial distribution provides the instantaneous mass flow rate or flux, $K_{\text {flux }}$, of the potassium element. Further integrating $K^{\Sigma_{f l u x}}$ in the time domain gives the released mass of the potassium element in a given burning stage (devol. or $C \& A$ ) as well as the total released mass of $K^{\Sigma}$. Fig. 4 shows $K^{\sum_{f l u x}}$ for corn straw and poplar. The stage (I) and (II) are separated by a blue dotted line. The method for determining the line can be found in Ref [15]. Both types of biomass have the highest $K^{\Sigma}$ release rate in the devol. stage, owing in part to the relative abundance of volatile matter in biomass. As with $\left[K^{A}\right]$ (Fig. $3 \mathrm{~b}$ ), the $K^{\sum_{f l u x}}$ profiles differ between the two biomass samples; the corn straw sample shows a signal maximum only during the devol. stage while poplar exhibits peaks in both the devol. and $C \& A$ stages. The total released mass of $K^{\Sigma}$ is $0.62 \mathrm{mg}$ for corn straw samples and $0.29 \mathrm{mg}$ for poplar samples, $94.7 \%$ and $81.8 \% K_{a d}$ (see Table 1), respectively. Dividing released $K^{\Sigma}$ into specific stages, corn straw releases $58.1 \%$ during the devol. stage and $41.9 \%$ for the $C \& A$ stage; the $K^{\Sigma}$ release for poplar is more balanced, with $48.3 \%$ occurring in the devol. stage and $51.7 \%$ in the $C \& A$ stage. The difference in physical and chemical characteristics between the forest and agriculture biomass [21] leads to differing combustion characteristics, such as catalytic action of alkali compounds during combustion.

Table 2 presents the summary data for $K^{A}$ and $K^{\Sigma}$ released from the two biomass samples. The CHEMKIN equilibrium model was used to predict the composition of atomic potassium and the other potassium compounds in the flame. The initial temperature and gas compositions were set to those predicted from the heat-flux burner. Moreover, the released chlorine and sulfur were assumed to be $\mathrm{HCl}$ and $\mathrm{SO}_{2}$ [22]. From the chemical equilibrium prediction, $\mathrm{KOH}$ is the most abundant form of potassium, and only $\sim 0.68 \%$ of the released potassium is in atomic form. This agrees well with our measured values of $0.77 \%$ for corn straw and $0.79 \%$ for poplar (Table 2 ). 


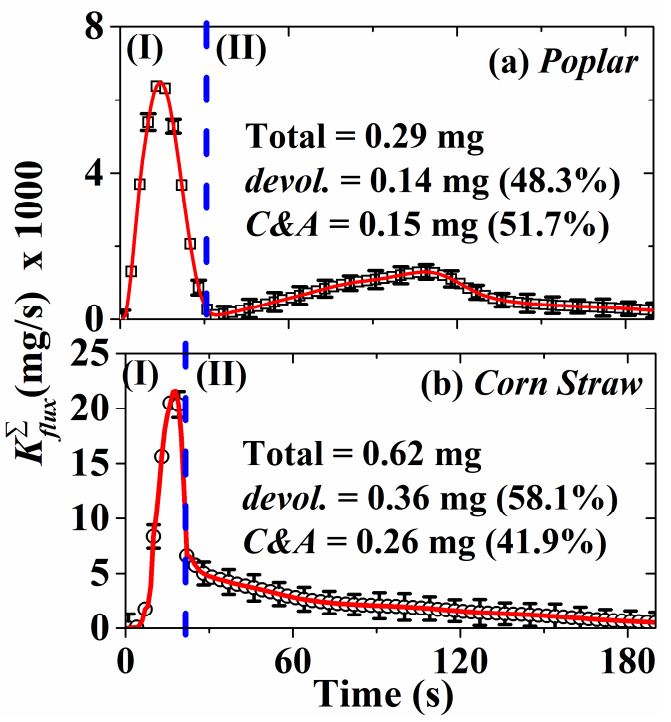

Fig. 4 Profile of $K^{\sum_{f l u x}}$ and statistics of $K^{\Sigma}$ release in different biomass-burning stages.

Table 2 Potassium release in different burning stages (raw biomass pellet: 50mg)

\begin{tabular}{ccccccc}
\hline & \multicolumn{3}{c}{ Poplar } & \multicolumn{3}{c}{ Corn Straw } \\
\cline { 2 - 7 } & devol & $C \& A$ & total & devol & $C \& A$ & total \\
\hline Atomic K $(\mu \mathrm{g})$ & 1.02 & 1.28 & 2.30 & 2.68 & 2.07 & 4.76 \\
Elemental K $(\mu \mathrm{g})$ & 140 & 150 & 290 & 360 & 260 & 620 \\
$K^{A}$ Proportion $(\%)$ & 0.73 & 0.85 & 0.79 & 0.74 & 0.80 & 0.77 \\
$K^{A}$ Proportion $(\%)$ & \multicolumn{5}{c}{0.68 at $1892 \mathrm{~K}$} \\
\begin{tabular}{c} 
by CHEMKIN \\
\hline
\end{tabular}
\end{tabular}

\subsection{Pellet Surface Temperature}

Temporal profiles of the biomass pellet's surface temperature $(T)$ during the combustion are shown in Fig. 5 .

As with $K^{\Sigma_{f l u x}}$ (Fig. 4) and $\left[K^{A}\right]$ (Fig. 3b), the data profiles of the two biomass samples are notably different, with a single maximum $T$ for corn straw during devol., and two maxima for poplar with one in the devol. stage and the other in the $C \& A$ stage. The dual maxima trend is similar to what has been observed from burning a coal pellet [13, 14], and is explained thus: (1) in Stage I, the pellet is rapidly heated up by the co-flow causing the release of volatile material, which produces a flame surrounding the pellet. This flame further heats the pellet until the volatile material is depleted; (2) in Stage II, the loss of heat from the volatile flame causes the pellet to cool slightly. The char begins to oxidize, again increasing the pellet temperature and leading to the second thermal peak for poplar; (3) in Stage III, the residual incombustible material in the pellet reaches thermal equilibrium with the 
surrounding environment. For poplar, the three stages can be determined as: Stage I, $0 \sim 26$ s; Stage II, $27 \sim 149$ s; and Stage III, $>149$ s. For corn straw, only two stages can be observed: Stage I, $0 \sim 22$ s; and Stage III, $>23$ s. The

lack of a second temperature peak during the corn straw $C \& A$ stage indicates that char oxidation proceeds in a different manner than that occurring in the poplar or coal combustion.

By calculating the temperature derivative in Fig. 5, the rate of pellet heating can be obtained. The maximum combustion due to heating from the gas flow and volatile combustion.

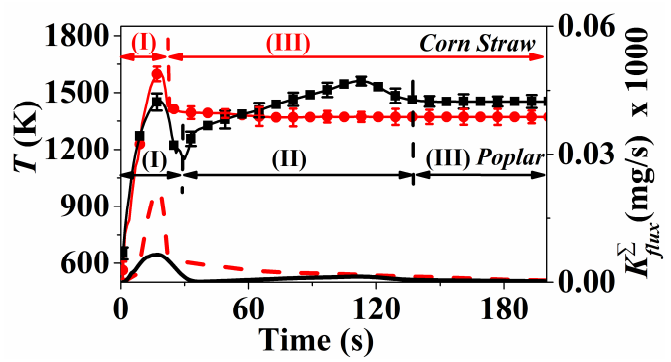

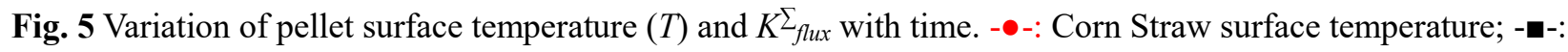
Poplar surface temperature; dash line: corn straw potassium release flux; solid line: poplar potassium release flux.

The temporal profiles of $T$ and $K^{\Sigma_{f l u x}}$ for corn straw and poplar are shown in Fig. 5. The devol. stage temperature peak is higher for corn straw than for poplar, despite poplar having a greater amount of volatile carbon. This with the lack of a $T$ minimum separating the devol. from $C \& A$ stage indicates that, for corn straw, char burnout occurs at an appreciable rate beginning in the devol. stage. This difference may be attributed to the structural difference in plant physiology between agricultural and woody type biomass [21], namely the greater lignification of the woody biomass cell walls.

\subsection{Kinetics}

Previous studies have related $K^{\Sigma_{f l u x}}$ to the particle temperature in combustion/gasification using a one-step 
(for biomass, it is the devol. stage). To improve the kinetic model, it is necessary to include two rate constants [14], one $\left(k_{V}\right)$ calculated from the devol. stage and the other $\left(k_{C \& A}\right)$ from the char and ash stage. For biomass samples, the one-step and two-step models have the same rate constant in the devol. stage. The empirically determined Arrhenius constant and the activation energy for each fuel sample are given in Table 3., where $Q_{K}$ is the total potassium mass $(\mathrm{mg})$ released during biomass-pellet combustion; $m$ is the pellet mass $(\mathrm{mg}) ; A$ is the pre-exponential factor $\left(\mathrm{s}^{-1}\right) ; E$ is the activation energy $(\mathrm{kJ} / \mathrm{mol}) ; R$ is the gas constant $\left(\mathrm{kJ} \mathrm{mol}^{-1} \mathrm{~K}^{-1}\right)$. By employing the measured surface temperature results for corn straw and poplar, predictions of $K^{\Sigma}$ release from both biomass samples is given in Fig. 6, including both the single and the two-step kinetics. The two-step model shows a clear improvement over the one-step model, providing significantly better predictions of $K_{f l u x}^{\Sigma_{f u}}$ in the devol. stage.

Table 3 Kinetics parameters of two models for biomass samples.

\begin{tabular}{lll}
\hline \multicolumn{1}{c}{ Kinetics Model } & Poplar & Corn Straw \\
\hline one-step: & & \\
$\left\{\begin{array}{lll}K_{f l u x}^{\Sigma}=Q_{K} \times k_{V} & A_{V}=4.64 & A_{V}=2.24 \\
Q_{K}=K_{a d} \times m \times\left(1-A_{a d}\right) & E_{V}=84.6 & E_{V}=64.8 \\
k_{V}=A_{V} \times \exp \left(-E_{V} /(R \times T)\right) & & \\
\hline\end{array}\right.$
\end{tabular}

$$
\begin{aligned}
& \text { two-step: } \\
& \left\{\begin{array}{lcc}
K_{f l u x}^{\Sigma}=Q_{K, V} \times k_{V}+Q_{K, C \& A} \times k_{C \& A} & A_{V}=4.64 & A_{V}=2.24 \\
Q_{K, V}=K_{a d} \times m \times\left(1-A_{a d}\right) \times V_{a d} & E_{V}=84.6 & E_{V}=64.8 \\
Q_{K, C \& A}=K_{a d}-Q_{K, V} & A_{C \& A}=20.5 & A_{C \& A}=15.3 \\
k_{V}=A_{V} \times \exp \left(-E_{V} /(R \times T)\right) & E_{C \& A}=55.4 & E_{C \& A}=62.8 \\
k_{C \& A}=A_{C \& A} \times \exp \left(-E_{C \& A} /(R \times T)\right) & &
\end{array}\right.
\end{aligned}
$$

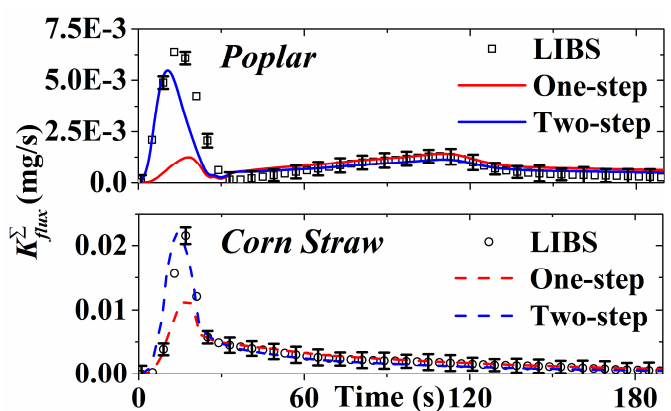

Fig. 6 Kinetic prediction of potassium release compared to LIBS data. 


\subsection{Transformation processes}

The processes by which alkali metals are transformed and released during biomass combustion have been discussed in [24]. A diagram of transformation processes is shown in Fig. 7, developed from [12, 23] and modified to include the catalytic oxidation reduction cycle of char-K. Potassium is initially classified as inorganic-K, which is found in the water fraction and mineral compounds and organic- $\mathrm{K}$, which is char- $\mathrm{K}$ and potassium bound to hydrocarbons not bound in the char. During combustion 5 pathways for release and 8 pathways for transfer between fuel components are suggested.

During the devol. stage, some organic-K is released into the gas phase by thermal decomposition (Pathway 1, P1) with the remainder being retained in the fuel (P2), e.g. carboxyl groups start to decompose in devoaltilization $-\mathrm{COOK} \rightarrow \mathrm{CO}_{2}+\mathrm{K}$. Inorganic- $\mathrm{K}$ is released into the gas phase through evaporation and thermal decomposition (P3), e.g. the decomposition of potassium carbonate $\mathrm{K}_{2} \mathrm{CO}_{3} \rightarrow 2 \mathrm{~K}+\mathrm{CO}_{2}+0.5 \mathrm{O}_{2}$, and some inorganic-K will react with organic structures in the biomass and be transformed to char-bound potassium (P4) [25], e.g. substitution of hydrogen by potassium in carboxyl groups $-\mathrm{COOH}+\mathrm{K} \rightarrow-\mathrm{COOK}+\mathrm{H}$. Additionally, inorganic-K can react with silicate, transferring potassium to the ash fraction (P5) [26], e.g. $2 \mathrm{KCl}+\mathrm{Al}_{2} \mathrm{O}_{3} \cdot 2 \mathrm{SiO}_{2}+\mathrm{H}_{2} \mathrm{O} \rightarrow \mathrm{K}_{2} \mathrm{O} \cdot \mathrm{Al}_{2} \mathrm{O}_{3} \cdot 2 \mathrm{SiO}_{2}$ $+2 \mathrm{HCl}$.

During the char burnout stage, potassium is found either bound to the char or as mineral compounds in the ash.

Thermal decomposition of the char leads to potassium release by increasing the vapor pressure of potassium compounds (P6), e.g. decomposition of char-K $-\mathrm{CK} \rightarrow \mathrm{K}$. Reaction with silicates will transfer potassium into the ash (P5) [25]. Oxidation processes in the char instigate multiple potassium conversion cycles: potassium release (P7a), transfer to ash of potassium oxides (P7b) and catalytic oxidation and reduction processes through cycling of $-\mathrm{CK}$ and $-\mathrm{COK}[11],-\mathrm{CK}+0.5 \mathrm{O} 2 \rightarrow-\mathrm{COK}$ and $-\mathrm{COK}+\mathrm{C} \rightarrow-\mathrm{CK}+\mathrm{CO}$.

Once the ash cooking stage is reached, all organically bound and water-soluble potassium has been released or transformed; but, potassium in the ash, e.g., $\mathrm{K}_{2} \mathrm{O}$, can react with the water vapor in the co-flow and generate $\mathrm{KOH}$ 


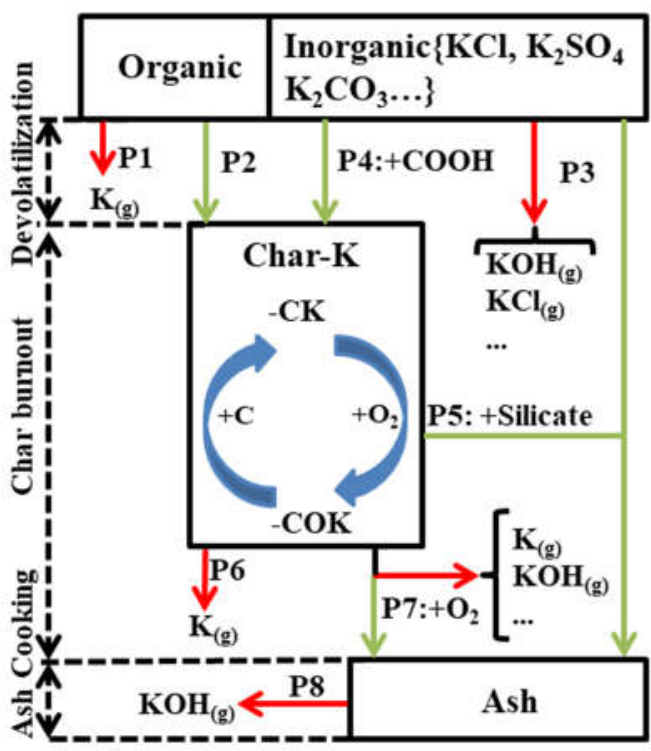

Fig. 7 Suggested potassium transformation mechanisms during biomass combustion.

\section{Conclusions}

The release and distribution of atomic and elemental potassium from two biomass samples (corn straw and poplar) have been measured throughout the duration of the biomass pellet combustion. Atomic potassium measurements were made using polarity filtered PLIF with simultaneous laser absorbance calibration; the elemental potassium concentration was measured using a calibrated multi-point LIBS apparatus. From both measurements the temporal profiles showed a single peak for corn straw (agricultural class) and a dual-peak distribution for poplar (forest class). In the devolatilization stage, the atomic and volatile potassium release is the strongest for the two biomass samples. The CHEMKIN predictions and experimental data agree well with each other. $\mathrm{KOH}$ is the major potassium compound in the gas phase at high temperature.

The kinetics of atomic and elemental potassium release for the two biomass samples has been correlated to measured pellet-surface temperature by a two-step model, which considers the contribution of both devolatilization and char burnout and produces more accurate predictions of potassium release than the existing one-step kinetics. 
sample, potassium may be divided into organic and inorganic groups. During the combustion, potassium may be

released or transferred between extant components of the fuel, i.e., char or ash. In addition, potassium associated

with the char component is involved in catalysis of char oxidation through an oxidation/reduction cycle. The $\mathrm{K}$

release in the devolatilization stage can be due to pyrolysis and evaporation; in the char burnout stage, it is due to

char oxidation and decomposition; in the ash cooking stage, it is caused by the reaction between the ash and $\mathrm{H}_{2} \mathrm{O}$ in

the co-flow.

\section{Acknowledgements}

This work was supported by the National Natural Science Foundation of China (51776185) and the Program

of Introducing Talents of Discipline to University (B08026). Financial support from the Royal Society and the

Engineering and Physical Sciences Research Council (EPSRC) of the UK is also gratefully acknowledged.

\section{References}

359 [1] S.E. Hosseini, M.A. Wahid, Renew. Sust. Energ. Rev., 40 (2014) 621-632.

360 [2] Y. Niu, H. Tan, S.e. Hui, Prog. Energy Combust. Sci., 52 (2016) 1-61.

361 [3] P.E. Mason, L.I. Darvell, J.M. Jones, A. Williams, Fuel, 182 (2016) 110-117.

362 [4] P.E. Mason, J.M. Jones, L.I. Darvell, A. Williams, Proc. Combust. Inst., 36 (2017) 2207-2215.

363 [5] C. Erbel, M. Mayerhofer, P. Monkhouse, M. Gaderer, H. Spliethoff, Proc. Combust. Inst., 34 (2013) 2331-2338.

364 [6] T. Sorvajärvi, N. DeMartini, J. Rossi, J. Toivonen, Applied spectroscopy, 68 (2014) 179-184.

365 [7] W. Weng, Q. Gao, Z. Wang, R. Whiddon, Y. He, Z. Li, M. Aldén, K. Cen, Energy Fuels, 31 (2017) 2831-2837.

366 [8] P. Van Eyk, P. Ashman, Z. Alwahabi, G. Nathan, Combustion and Flame, 155 (2008) 529-537.

367 [9] L.-J. Hsu, Z.T. Alwahabi, G.J. Nathan, Y. Li, Z. Li, M. Aldén, Applied spectroscopy, 65 (2011) 684-691.

368 [10] Y. Yuan, S. Li, Q. Yao, Proceedings of the Combustion Institute, 35 (2015) 2339-2346.

369 [11] P.J. Van Eyk, P.J. Ashman, G.J. Nathan, Combust. Flame, 158 (2011) 2512-2523.

370 [12] Z.-h. Zhang, Q. Song, Z.T. Alwahabi, Q. Yao, G.J. Nathan, Combustion and Flame, 162 (2015) 496-505.

371 [13] Z. Wang, Y. Liu, Y. He, R. Whiddon, K. Wan, J. Xia, J. Liu, Energy \& Fuels, 30 (2016) 8977-8984.

372 [14] Z. Wang, Y. Liu, R. Whiddon, K. Wan, Y. He, J. Xia, K. Cen, Combustion and Flame, 176 (2017) 429-438.

373 [15] Y. Liu, Y. He, Z. Wang, K. Wan, J. Xia, J. Liu, K. Cen, Combustion and Flame, 189 (2018) 77-86.

374 [16] Y. He, J. Zhu, B. Li, Z. Wang, Z. Li, M. Aldén, K. Cen, Energy \& Fuels, 27 (2013) 1123-1130.

375 [17] T. Dzubay, B. Jarrett, J. Jaklevic, Nuclear Instruments and Methods, 115 (1974) 297-299.

[18] S. Bejaoui, X. Mercier, P. Desgroux, E. Therssen, Combustion and Flame, 161 (2014) 2479-2491.

[19] P.J. van Eyk, P.J. Ashman, Z.T. Alwahabi, G.J. Nathan, Combust. Flame, 158 (2011) 1181-1192.

378 [20] L.L. Baxter, R.E. Mitchell, T.H. Fletcher, Combust. Flame, 108 (1997) 494-502.

379 [21] O. Senneca, Fuel Process. Technol., 88 (2007) 87-97.

380 [22] M. Bläsing, M. Müller, Energy Fuels, 26 (2012) 6311-6315. 
381 [23] H. Fatehi, Y. He, Z. Wang, Z. Li, X.-S. Bai, M. Aldén, K. Cen, Proceedings of the Combustion Institute, 35 (2015) 382 2389-2396.

383 [24] J.M. Johansen, J.G. Jakobsen, F.J. Frandsen, P. Glarborg, Energy Fuels, 25 (2011) 4961-4971.

384 [25] S.C. Van Lith, V. Alonso-Ramírez, P.A. Jensen, F.J. Frandsen, P. Glarborg, Energy \& Fuels, 20 (2006) $964-978$.

385 [26] J.N. Knudsen, P.A. Jensen, K. Dam-Johansen, Energy Fuels, 18 (2004) 1385-1399. 